\title{
Teaching of Intercultural Communication for Business Professionals in Business Training Project
}

\author{
Jin Wang \\ Business English Department \\ Tianjin University, Renai College \\ Tianjin, China
}

\begin{abstract}
Under the unprecedented high-speed globalization, China with its economy is playing a remarkable and influential role in international business. The "Going-out" as and "One Belt, One Road" strategies demonstrate China's open and collaborative attitude toward international cooperation and interaction. Under this new and prosperous international business environment, Chinese enterprises are meeting fiercer challenges as well as numerous business opportunities. In order to catch up with this new situation, companies now are in huge demand of competent professionals and talents. A perfect staff is expected not limited to a single skill but to possess both professional knowledge and good intercultural business communication ability. This requirement encourages the emerging business English training, which is considered as a kind of efficient businessuniversity collaboration. This kind of training projects aims to consolidate business people's language knowledge, to improve their communicative ability for participating in practical business negotiations and tackling problems and conflictions, and most of all, to elevate their intercultural business communication proficiency. Literature tells that both theoretical and empirical researching focus has been cast on intercultural communication for business English major students in colleges but seldom for training business professionals in enterprises. Therefore, this paper aims to explore the existing condition of teaching and practicing of intercultural communication for business people, focusing on the discrepancies of teaching strategy and performative evaluation between business professionals and college students in respect of four dimensions. The study is supported by the author's own teaching practice in a business English training project and results from interviews and a questionnaire are presented to showcase the facts of bilateral teaching and learning reactions, endeavoring to find practical and reasonable pedagogy for intercultural business communication training.
\end{abstract}

Keywords—globalization; intercultural business communication; business English training; discrepancy; pedagogy

\section{INTRODUCTION}

Under the unprecedented high-speed globalization, China with its economy is playing a remarkable and influential role in international business. The "Going-out" strategy as well as "The Belt and Road" initiative demonstrate China's open and collaborative attitude toward international cooperation and interaction. Under this new and prosperous international business environment, Chinese enterprises are meeting fiercer challenges and numerous business opportunities. In order to catch up with this new situation, companies now are in huge demand of competent professionals and talents. A perfect staff is expected not limited to a single skill but to possess both professional knowledge and good intercultural business communication (IBC) ability. Hall (1990) acknowledges that intercultural communication competence can be defined as a unique manner possessed by an individual who wants to realize his character, goals, and expectations in a specific environment. This requirement encourages the emerging business English training, which is considered as an efficient business-university collaboration This kind of training project aims to consolidate business people's language knowledge, improve their communicative ability to participate in practical business negotiations, to tackle with problems and conflictions, and most of all, to elevate their intercultural business communication proficiency.

Literature tells that both theoretical and empirical researching focus has been cast on intercultural communication for business English major in colleges but seldom for training business professionals in enterprises. Therefore, this paper aims to explore the existing condition of teaching and practicing of intercultural communication for business people, focusing on the discrepancies of teaching strategy and performative evaluation between business professionals and college students. The study is supported by the author's own teaching practice in a business English training project and results from interviews and questionnaires are presented to showcase the bilateral teaching and learning reactions, endeavoring to find practical and feasible pedagogy for intercultural business communication training.

\section{THE NECESSITY OF CULTIVATING INTERCULTURAL COMMUNICATION COMPETENCE IN BUSINESS ENGLISH TRAINING}

According to Wikipedia, business English is English language especially related to international trade. So, business English training is language training for special purpose. Nowadays, many professionals study the subject with the goal of communicating and doing business with 
English-speaking countries, or with companies located outside the Anglosphere but which use English as a shared language or lingua franca. Hence, business English training entails intercultural communication. Apart from linguistic knowledge, there is a truth universally acknowledged that intercultural communication is inescapable in business English learning. The ultimate objective of business English learning is to acquire intercultural communicative competence which is the ability to understand both language and behavior of a target community. Against the backdrop of economic globalization, China, as the biggest developing country in the world, is playing an active and influential role. There is no doubt that China is in great demand of professionals with satisfying intercultural communication competence. Moreover, world economy also needs a bridge over cultural barriers.

\section{EMPIRICAL ANALYSIS: AN INTERCULTURAL BUSINESS COMMUNICATION TRAINING EXAMPLE}

\section{A. Introduction}

The practicing teaching example of intercultural communication is between China Gezhouba Group Company Limited and Tianjin University. Gezhouba Company is a Chinese construction and engineering company based in Wuhan, Hubei Province. Nowadays, the company has been very keen to expand overseas business with a stated goal of increasing international contracts. Its overseas projects include a 4.97-billion-yuan contract signed in 2010 with Kazakhstan Natural Gas Technology to establish a hydroelectric plan and in November 2014, the firm was also chosen to a construct a $40 \mathrm{~km}$ portion of the Hazara Motorway in Pakistan. The company set up a "1000 talents" project; collaborating with Tianjin University (Tianjin University as one collaborator) to train its elite staff members to improve intercultural business communication ability. The project started from March 2014 and is expected to end in December 2017.

\section{B. Preliminary Evaluation and Curricular Plan}

Before the training project, there is fundamental investigation about the trainees. According to statistics, in each class (35 trainees more or less), more than $80 \%$ of the trainees passed CET (College English Test) 4 and less than $15 \%$ passed CET 6 in their colleges. According to the motivation investigation, approximately $25 \%$ of the trainees admitted that they were required to participate in the project by their company rather than of their own accord. As for the expectation from the project, more than $50 \%$ of the trainees hope to improve basic language proficiency, while only $20 \%$ of them expect to enhance their cross-cultural communication ability.

Before the training part, every class member is required to take a pre-training test. The test is a past CET 4 paper; however, the result is not satisfactory. The average passing rate is not more than $30 \%$. On reflection, there are several reasons for the result: First, trainees didn't make preparations before the test. Second, they haven't used English after graduation for a certain long time. Third, they haven't been used to the new learning environment. Fourth, some of the trainees may have mental rejection of the training project. In general, it is apparent that there exist tough problems and the training situation for professionals is quite different from that for university students.

The training project is a full-time program which lasts for 9 months for each class. Trainees are allocated randomly into each class and their language levels are quite different. The selected training courses mainly include business writing, engineering English reading, business English: listening and speaking, international business etiquette, international business negotiation, FIDIC (Fédération lnternationale Des lngénieurs Conseils) conditions of contract, et cetera. According to Mark Ellis and Christine Johnson, they put up five business skills in their representative work Teaching Business English: An Introduction to Business English for Language Teachers, Trainers, and Course Organizers. They are negotiation skill, information skill, phone communication skill, business writing skill and socializing skill. The courses in the training project are designed in conformity with the above-stated objectives and make an effort to create virtual business English environment to help trainees to practice and develop intercultural communication ability and teamworking spirit.

\section{Performance Monitoring and Evaluation}

The training is a long and painstaking one for both trainers and trainees. During the lengthy training period, several problems emerged. The following is a performative analysis of trainees in four dimensions: vocabulary, syntax, register and culture.

1) Vocabulary: Vocabulary is part and parcel for language study. Throughout the whole span of business English training, every course emphasizes the importance of vocabulary as the basis. According to the interviews with all the teachers/trainers, many different forms of tests are taken regularly in classes to help students strengthen words memory. However, the result is not satisfactory. Apart from the small quantity of words, it is noticeable that most mastered words for the trainees are common words in daily life. However, Fixed terms and expressions are unfamiliar to them. Almost all teachers believe that an average trainee's vocabulary level is inferior to that of a college student.

2) Syntax: According to the feedback of teachers/trainers, most trainees know only simple grammar and with small vocabulary, they often speak and write ungrammatical sentences. What is even worse is that some trainees can only use simple words and phrases to express their views. Sentences they write are almost out of Chinese thinking pattern, which results in misunderstanding.

3) Register: Register in linguistics refers to a variety of a language used for a particular purpose or in a particular social setting. No language is used in vacuum. Communication always takes place in a certain context and business English communication always takes place in business activities. Therefore, it cannot be neglected that 
business English training should help trainees cultivate register consciousness. However, in practice, trainees don't have sharp register consciousness. Most trainees lack the ability to identify different degrees of formality of business situations. Their usage of words and sentences tend to be consistently colloquial and informal.

Lack of register consciousness reflects the inadequacy of cultural consciousness, which refers to an understanding of one's own and others' cultures that affect how people think and behave, which includes understanding commonalities of human behavior and differences in cultural patterns. Without clear cultural awareness, people can hardly achieve successful business communication. To cultivate intercultural awareness is essential in business English communication training.

4) Culture: Hoebel and Frost (1976) say culture is an integrated system of learned behavior patterns which are characteristic of the members of a society and which are not the result of biological inheritance. Hu (1999) believes that language is both the carrier and a raw portrayal of culture. One of the difference between professional trainees and college students is that the most trainees have working experience abroad. To some degree, this fact facilitates the infusion of intercultural awareness to trainees in classes. According to the teaching experiences, most teachers recall that trainees are very interested in intercultural topics and discussions in class. They are willing to share their communicating experiences with foreigners and even their awkward experiences. What is more interesting is that, more often than not, trainees question inappropriate settings or unpractical exercises in textbooks. Trainees' working experience enrich and improve some part of the teaching. This kind of interaction should be valued and can be hardly found in college classrooms.

Nevertheless, trainees have their own shortcoming in intercultural communication. Although it seems that they have equipped with intercultural awareness thanks to their working experience, in real business communication, they could hardly make fully use of their advanced consciousness, to be exact, they could not transform their intercultural communication consciousness into implementation. This deficiency is the most striking difference between professionals and college students. In recent years, business English teachers in Chinese universities tend to emphasize the importance of intercultural communication in their teaching and pedagogies. Intercultural education is becoming an indispensable part for business students who lack the intercultural awareness due to their little experience in the working world. However, the trainees are just in an opposite position. The vast majority of them do have working experience, and in real work, they have been touching and experiencing intercultural interaction. They know better than students about what cultural shock is. What disturbs the professionals is how to tackle with intercultural communication barriers. They are often at lost when facing intercultural issues. According to the interviews of trainees in the project, one of them told the author that in his work, when he could not communicate successfully with foreign business people, he tended to be confused. He realized that there must be something wrong with delivery of his idea, but not the idea itself. When facing this kind of situation, he would resort to translators for help. But he expressed his hope to know how to solve the problem in the training project.

\section{CONCLUSION}

From the author's observance and empirical research, it is found that there exists obvious discrepancy between IBC education for professionals and students. Most professionals have weak language basis, but have more experience in work. According to the survey, $70 \%$ of the trainees consider rich working experience as their biggest strength for this project. They have strong intercultural awareness than students but lack intercultural implementation. The root of this deficiency lies in their limitation of language expression and situation practicing. More than $60 \%$ of the trainees acknowledge that low language proficiency is their biggest weakness for this project.

Therefore, during the training project introduced in the paper, many tailor-made practices and activities are designed for trainees. First is to consolidate the basic business terms and expressions in class and after class. Basic language knowledge is the preliminary step for successful business communication. Business English has its own language features, like preciseness of expression, usage of terms and abbreviations, fixed language style. Teachers must emphasize this point to trainees and supervise them to grasp what is covered in classes every day. Second is to provide trainees with suited in-class activities. According to the survey, more than $70 \%$ of the trainees prefer case analysis and discussion in class. This activity can be implemented by subgroups. Most trainees are interested in genuine cultural cases analysis and have passion to participate in discussions. They believe this is the most effective way to learn than cramming study. The second frequently implemented activity is situation performance. Situational teaching method is an active teaching method which is studentcentered. In classes, trainees are given different virtual business situations. They need to think out the solutions, organize their expressions and design appropriate body language. The total work helps trainees accumulate experience in solving intercultural communication problems and also strengthen their language performance. The third popular activity is lecture. Many experts and foreign teachers are invited to classroom to share with trainees their precious working stories. Similar working background facilitates smooth and sincere communication between lecturers and trainees. The lectures aim to broaden trainees' vision and deliver useful suggestions. Trainees get deeper understanding about cultural differences and business etiquette, and they are stimulated and have confidence to finish the training project.

The evaluation of the whole training project also sheds light on some certain interesting discoveries. According to the survey, more than $85 \%$ of the trainees recognize business English: listening and speaking and FIDIC conditions of 
contract are the two most difficult and beneficial courses. The dual importance reflects that professionals know well both technical ability and cross-cultural communication ability are essential and more than $90 \%$ of the trainees believe intercultural communication awareness and ability are important in real work. However, in spite of the above fact, more than $70 \%$ of the trainees insist that cultural discrepancy is so big that the gap can never be bridged. This feedback from experienced professionals may bring some insight into intercultural communication teaching and enlighten business English teachers to rethink about the value and feasible teaching pedagogy. As $\mathrm{Fu}$ (2008) comments, Business English training should make a valuable contribution to intercultural competence training by changing focuses from an abstract and formalistic knowledge and concept study of language and business regularities to concrete and practical cultivation of language competence and workable business skills used in society and in international business fields.

\section{REFERENCES}

[1] H. Edward, The Hidden Dimension. New York: Anchor, 1988.

[2] H. Edward Adamson, and F. Everett Lloyd, Culture and Social Anthropology. New York: McMraw-Hill, 1976.

[3] W. Chunrong, "A Probe into Cultivation of Intercultural Communication Competence in Business English Learning." International Journal of English Language Teaching, Vol. 3, p. 57, 2016.

[4] Fu. Zhiyi, "A Study of How to Develop Students' Intercultural Communication Competence (ICC) in Business English Teaching (BET)." Asian Social Science, vol. 4, p. 84, 2008. 